\title{
THE FLIGHT OF TWO THOUSAND MARKED MALE MEDITERRANEAN FRUIT FLIES (CERATITIS CAPITATA WIED.).
}

Henry H. P. Severin, Ph. D., Honoraty Fellow, University of Wisconsin, and William J. HaRtung, B. S.

Mally (1, p. 8) Entomologist for the Eastern Province, Cape Colony, South Africa, discusses the migration of the adult Mediterranean fruit fly as follows: "There is no evidence to show how far the adults will travel in their search for food. Some observers think they migrate but very little, citing instances where well-kept premises have been fairly free although in close proximity to neglected and badly infested ones. Under such conditions there is no necessity for migration, ample foodsupply being already at hand. There is no clear evidence to. show how they get to new orchards on farms where fruit trees have never been grown before. Men who have laid out new orchards say that the 'maggot' was in evidence the first time the trees came into bearing. *** It is a popular belief that the flies come in from the veld. The most unrelenting search has failed to demonstrate their presence in bush or veld 500 yards. from an orchard."

"Prevailing winds are perhaps the most potent factor. How far the flies are liable to be carried by the wind it is impossible. to say. One would hardly expect that they would be blown very far at once. It seems easily within the range of possibility that they should be involuntarily caught up by the wind when they attempt to fly and lodge on a bush or in the veld some distance away; and then be caught up again and carried still farther, and so on indefinitely. There is little doubt that certain Aphididæ do make use of the wind in migrating to their secondary host plant, but I have found nothing to indicate the presence of the same trait in the fruit fly.'

Newman 2, (p. 7) Entomologist of Western Australia writes. as follows concerning the migration of the Mediterranean fruit fly: "This fly is not an insect that migrates any great distance. As long as a food supply is available, it remains in an orchard. I have known instances where one orchard was swarming with the pest and the one next door or on the opposite side of the street was perfectly clean. Strong winds are the most potent factor in the spread of the fly; there is no saying how far she may be carried." 
The conditions existing in South Africa are entirely different from those in Honolulu and the outskirts of this city where our experiments on the flight of the marked Mediterranean fruit flies were performed. There are only a very few small orchards in and around the city of Honolulu but in practically every dooryard surrounding a residence a great variety of fruits are grown such as various kinds of citrus fruits, coffee, figs, garden varieties and wild guavas, mangoes, papaias, peach, plum, rose apple, tropical almond (umbrella tree or "kamani" nuts) sour sop, star apple, etc., from which we have bred the pest. These cultivated fruits ripen at different times of the year and offer the insect a regular succession of fruits in which to breed. In the uncultivated as well as in the mountainous districts of Honolulu the prickly pear which is also attacked by the fly is scattered over large areas. Different species of wild guaves which are hosts of the pest cover thousands and thousands of acres on the slopes of the mountains, in the gulches, in uncultivated portions of the valleys and plains, along the banks of streams and along some of the roads and paths leading from the city. These different species of wild guavas bear fruit practically the year around. Other wild fruits which the insect attacks are the mountain apples and the wild coffee berries. The climatic conditions in the Hawaiian Islands are also very favorable for the development of this trypetid, a generation of flies appearing about every four or five weeks throughout the year. In the city of Honolulu there is thus, a regular succession of cultivated fruit for the fruit fly to breed in, and in the outskirts of the city and in the mountainous districts wild fruits are available for the pest during the entire year.

In order to determine positively the powers of flight of the Mediterranean fruit fly, two thousand male specimens, which were bred in the laboratory from infested fruits, were handled and marked so that they would be injured as little as possible by employing the following methods: Hundreds of fruit flies were liberated under a small cheese-cloth tent which was fastened at its base to the three sides of a table and at its apex to the ceiling by a string. The head and shoulders were thrust under the tent at the open side and each specimen was captured in a small vial: The fly within the vial was seized by one wing with a pair of forceps, around the end of one prong a small elastic band had been wound. The fruit fly held by one wing, 
was then placed upon a piece of white paper and usually in endeavoring to free itself, the fly would extend, spread and then catch hold of the paper with the legs on the opposite side of the body from the imprisoned wing, and attempt to pull its body away from the forceps. With the limbs in this position any leg on one side of the body could be easily cut through with either a sharp, spear-pointed or triangular-shaped needle, without danger of injuring the other appendages.

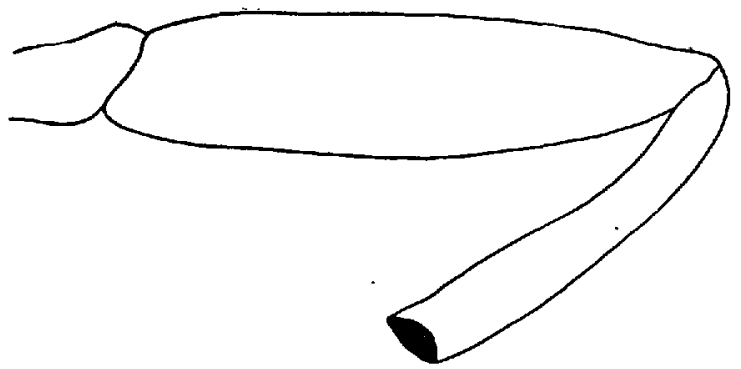

Fig. 1. Middle leg of Mediterranean fruit fly cut through the tibia. This. specimen thus marked had been set free from the side of a mountain at an elevation of about three hundred fifty feet and was captured in a kerosene trap a mile and a half from the point of liberation.

After the amputation, the flies were put into breeding jars for a number of days to allow the wounded leg to heal. During this time they were fed with dilute molasses and water. The molasses was daubed on the sides of the jars by means of a camel's hair brush, while the water was sprayed into the jars in the form of a mist. The tops of the jars were covered with cheese cloth to allow free circulation of the air and the bottom of the jars were covered with sand to absorb the access of moisture and molasses.

The two thousand marked male flies were liberated on the outskirts of Honolulu in Manoa Valley which is walled in by mountains on all sides except the seaward side. This valley is more than two miles in length; in width, it varies from a half mile at the head end to a little more than a mile at its mouth, the greater portion of the valley being about three-quarters of a mile wide, (Pl. XXIX). The elevation of the mountains surrounding this valley varies from two thousand to two thousand five hundred feet at the head end but gradually becoming lower towards the mouth, (Pl. XXIX). At some places the sides of 
the mountains rise very abruptly but in general the slope is quite gradual. The bottom of the valley consists largely of taro patches, (P1. XXX).

At the head end of the valley, in a circle about a half mile in diameter, fifty kerosene traps were wired among the branches of citrus, fig, guava, hau and tropical almond trees. In a previous experiment we found that of every thousand Mediterranean fruit flies captured in kerosene only three were females and for this reason only marked males were used.

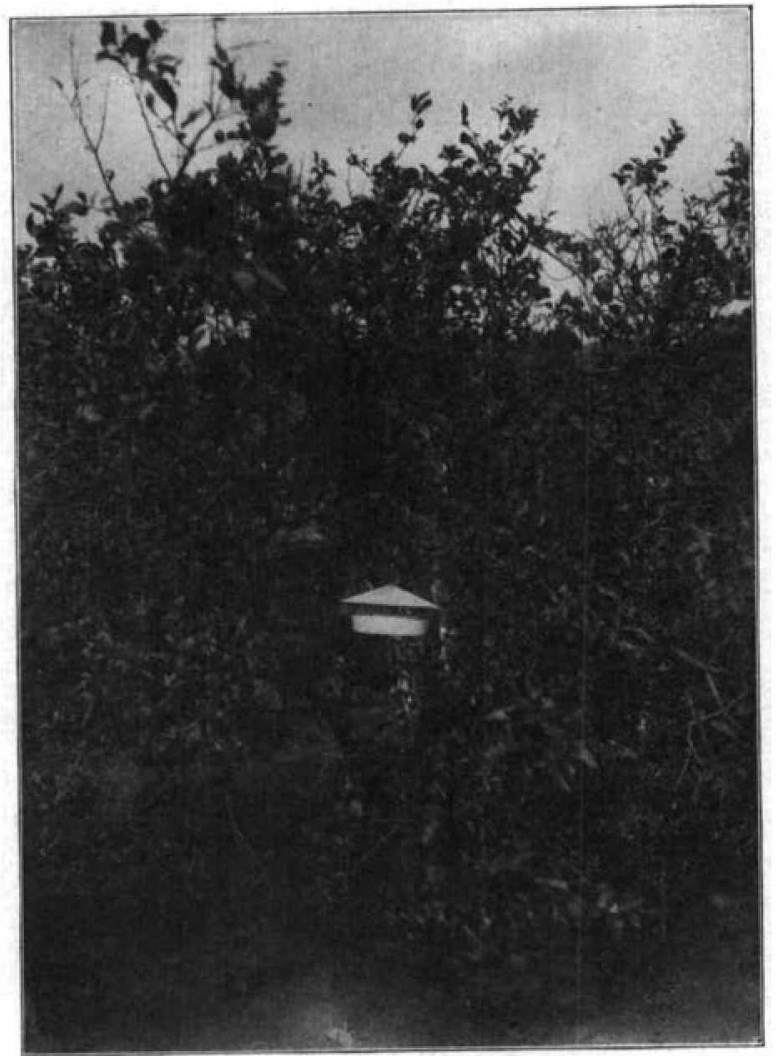

Fig. 2. Kerosene trap wired to a branch of a lemon tree. The white enameled pan containing the oil is covered with a galvanized iron cover to keep out the rain. The fruit flies enter the trap in the space between the cover and the rim of the pan.

The Mediterranean fruit flies were set free in lots containing from two to six hundred specimens. When the first lot of flies were set free, the jars containing the marked individuals were 
held on a level with the eye to better enable the observer to note the direction of flight. In order to arouse the flies into activity and hasten their departure, the sides of the jars were snapped lightly with the fingers, with other lots, however, the jars were placed upon the ground and the males were allowed to escape. With the sky as a background, the unaided eye could follow the insects in their flight to a distance of about a hundred feet, but with the use of a field glass, the flies could be followed to a much greater distance.

While liberating the first lot of five hundred fruit flies in the center of the circle of traps it was observed that the wind played an important part in their direction of flight. A heavy northeast wind was blowing from the mountains to the sea, while these marked diptera were liberated, and it was striking to note that they flew and were carried with the wind down the valley with extreme rapidity towards the city of Honolulu. Since the prevailing winds at this time of the year are from the northeast, a change in the arrangement of the traps was made. The traps that had been located in that half of the circle nearest the head end of the valley, were placed amongst the trees of two citrus grooves, (P1. XXX,4), situated on the leeward side of the remaining semicircle of traps. (Pl. XXX, white line.)

The trypetids were liberated from three different points. As was already mentioned five hundred fruit flies with the hind leg cut, were liberated in the center of the circle of traps, about a half mile in diameter. After the traps had been rearranged a thousand specimens with the front leg severed were set free from the head end of the valley about a half mile from the traps. Five hundred males with the middle leg amputated were freed at the head end of the valley from the side of a mountain at an elevation of about three hundred fifty feet and at a distance of about one mile from the traps. A glance at the photograph shows the three points of liberation.

(P1. XXX, 1, 2, and 3).

The orientation of the marked individuals was carefully noted with the liberation of each lot of flies under the different climatic conditions. Whenever a heavy or light north-east wind blew from the mountains to the sea, the insects as soon as liberated would orient themselves with the wind and fly down the valley but when a south-west wind from the sea to the mountains prevailed, the specimens again oriented themselves 
with the wind and in this case flew up the valley towards the mountains. In no case did the fruit flies attempt to orient themselves against even the lightest breeze. During calm spells no orientation took place and the flies darted off in all directions.

From time to time some of the kerosene traps were moved. farther and farther into the city of Honolulu and were again hung among the branches of fruit bearing trees, usually citrus trees. These traps were visited every day, the fruit flies captured in a trap were put into a vial labeled as to the location of the trap. The kerosene was renewed daily in each trap.

The varying climatic conditions under which the different lots of flies were set free are indicated in the following table:

TABLE I.

\begin{tabular}{|c|c|c|c|c|c|}
\hline \multirow{2}{*}{ Date } & \multirow{2}{*}{$\left|\begin{array}{c}\text { No. of } \\
\text { Flies } \\
\text { Lib- } \\
\text { erated }\end{array}\right|$} & \multirow{2}{*}{$\begin{array}{l}\text { Leg } \\
\text { Cut }\end{array}$} & \multicolumn{2}{|c|}{$\begin{array}{c}\text { Conditions of weather at time of } \\
\text { liberation }\end{array}$} & \multirow{2}{*}{$\begin{array}{c}\text { Total pptd. } \\
\text { U. S. } \\
\text { Weather } \\
\text { Report }\end{array}$} \\
\hline & & & Winds & Precipitation & \\
\hline $\begin{aligned} & \text { Feb. } \\
& 21\end{aligned}$ & 500 & Hind & Heavy N. E. & Frequent heavy rains & .72 \\
\hline 24 & 600 & Front & Light N. E. & $\begin{array}{l}\text { Light rains, occasional } \\
\text { heavy showers. }\end{array}$ & 1.12 \\
\hline 25 & 200 & Front & $\begin{array}{c}\text { Gusts of N. E. } \\
\text { and } \\
\text { Calm Spells }\end{array}$ & No rain. & .26 \\
\hline 26 & 200 & Front & $\begin{array}{c}\text { Light N. E. } \\
\text { and } \\
\text { Calm Spells }\end{array}$ & No rain. & .21 \\
\hline 29 & 500 & Middlo & $\begin{array}{l}\text { Moderate } \\
\text { S. W. }\end{array}$ & No rain. & .00 \\
\hline
\end{tabular}

The total number of fruit flies captured during one month in the fifty kerosene traps was two thousand three hundred and nine, of this number one hundred fifteen were marked specimens from the two thousand that had been liberated. Of the marked individuals captured there were seventy-three with the front leg cut, eleven with the middle leg and thirty-one with the hind leg. Most of the one hundred fifteen marked insects. were captured during the first fifteen days after the experiment had been started. 
The first lot of five hundred Mediterranean fruit flies were set free during light rains followed by frequent heavy showers and yet thirty-one of these marked specimens were captured in the kerosene traps; apparently the drops of rain striking the fruit flies did not disable them for flight. The last lot of five hundred marked males was liberated while a south-west wind was blowing away from the city of Honolulu towards the mountains and yet eleven of these marked individuals were captured in kerosene traps located in the outskirts of the city at distances varying from a mile to a mile and a half from the point of liberation. The explanation of this fact may be that some of these marked insects were caught up by changes of wind carrying them first towards the mountains and then back again into the city of Honolulu.

Marked Mediterranean fruit flies were captured at distances varying from a quarter of a mile to a mile and a half from their respective points of liberation. In all probability some of the flies which had been set free during a strong wind were caught up and carried far into the city of Honolulu or even way beyond into the sea miles away from the points of liberation. In numerous instances kerosene traps were kept in the same tree for a period of two weeks and marked specimens were captured from time to time. The explanation of this fact may be that the fruit flies did not make one continuous flight from the point of liberation to the trap in which they were caught, or that the trypetids were not immediately attracted to the kerosene after getting into the vicinity of them.

On account of using male fruit flies only, the argument may be raised that there is no evidence from this experiment that the female flies are carried by the winds. How would the rapid distribution of the pest in the guava belt, often at high altitudes in the mountains, be explained? In all probability the answer to this question is best explained by the fact that the wind, which is such a potent factor in influencing the flight of the males, as demonstrated by this experiment, has carried the females as well as the males into the guava belt.

Clean culture to control the Mediterranean fruit fly as carried on by the Board of Agriculture in the Hawaiian Islands consists in stripping all fruit trees, except mangoes and papaias of infested and ripe fruit and also of picking up and destroying 
fallen fruit. Attention has already been called to the fact that the wild guavas which are available for the pest to breed in during the entire year cover thousands and thousands of acres in the mountainous districts. If only a small per cent of the fruit flies breeding in these wild fruits are caught up by the winds blowing from the mountains towards the city of Honolulu, what ultimate results can be expected from the clean culture methods of the present Mediterranean fruit fly campaign!

After sending this manuscript to the editor we received from Dr. A. Berlèse a paper entitled, "Expériences Exécutées en Italie pour Combattre la. Mouche des Oliviers." presented at "Ier Congrès International d'Oléiculture: (Toulon, 1908)" in which he states that the olive fly, Dacus oleae Rossi obeys "l'instinct de diffusion, émigrent au loin, à la recherche de nouveau ambients.

En outre, dans la première génération printnaière-estivale l'instinct de migration se montre très développé chez les femelles. A cette époque l'on constate que certaines émigrations couvrent de grandes distances. Cela est: éstrange, lorsqu'on pense a la commodité qu'auraient les mouches àdéposer, a. cette époque, leurs oeufs là ou elles sont nées. Au contraire, elles vont parfois les pondre à plusieurs kilomèters ( $k-3,280.8$ feet) de distance."

We are deeply indebted to Prof. Harry C. Severin, State Entomologist of South Dakota, who has given us valuable suggestions in reading the manuscript: with us.

\section{BIBLIOGRAPHY.}

1. Mally, C. W., 1904. The Fruit Fly (Ceratitis capitata, Wied.). Repr. Agric, Jour. Dec. No. 28, Cape of Good Hope. pp. 1-18.

2. Newman, L. J., 1910 . Fruit Fly. Dept. Agric. and Industries, Western Australia, Bull. 38, pp. 1-11.

\section{EXPLANATION OF PLATE XXIX.}

Map of Manoa Valley. This valley is walled in by mountains on all sides except the seaward side. The elevation of the mountains are indicated. The two thousand marked, male Mediterranean fruit flies were liberated at the head end of the valley.

EXPLANATION OF PLATE XXX.

Head end of Manoa Valley. Some of the fifty kerosene traps wcre wired among the branches of fruit trees situated along the white line. 1, 2, and 3 points of: liberation of the two thousand marked, male Mediterranean fruit flies. 4, Citrus grooves. (Reproduced by permission of $\mathbf{E}$. Bonine, photographer.) 


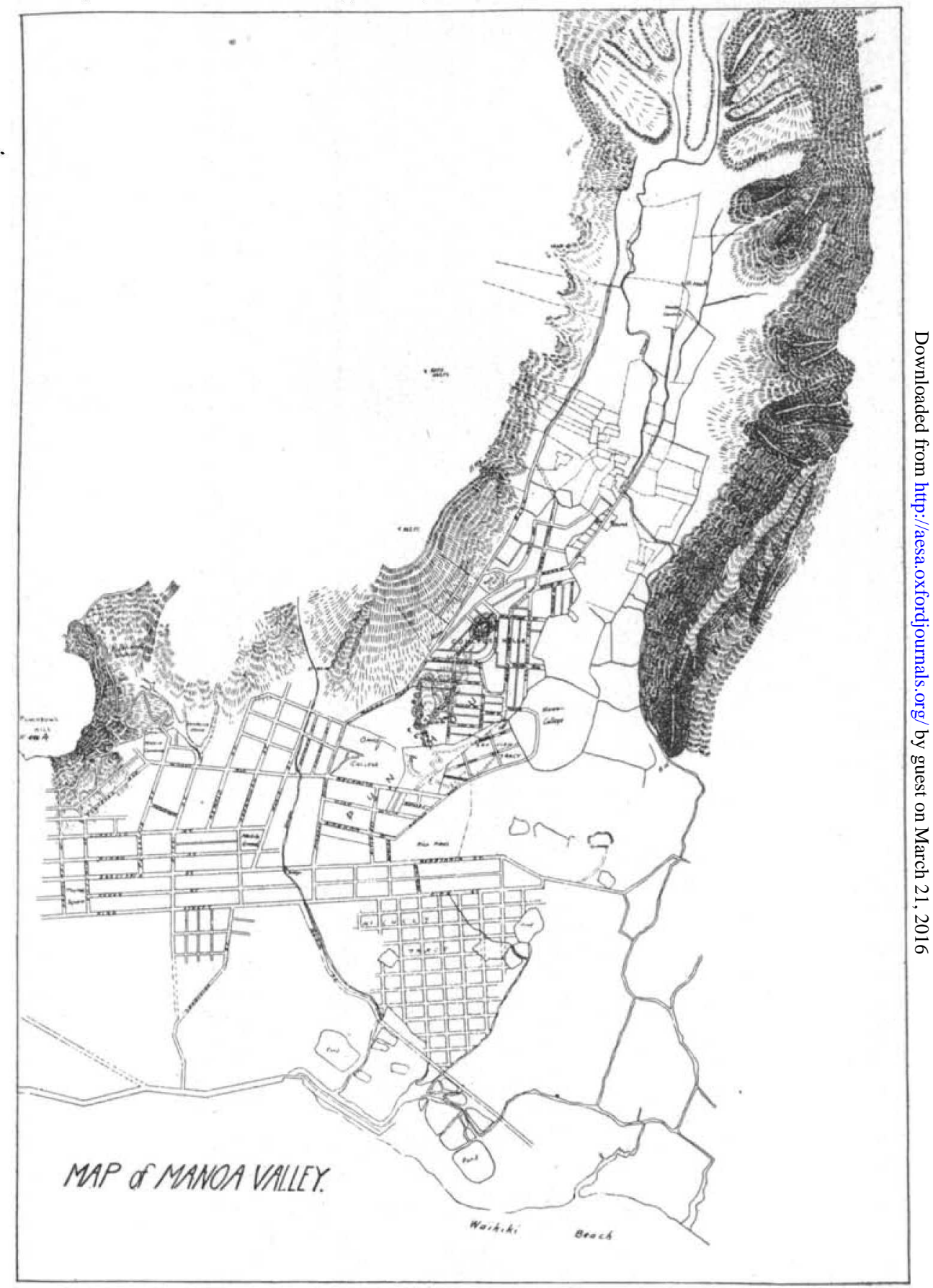




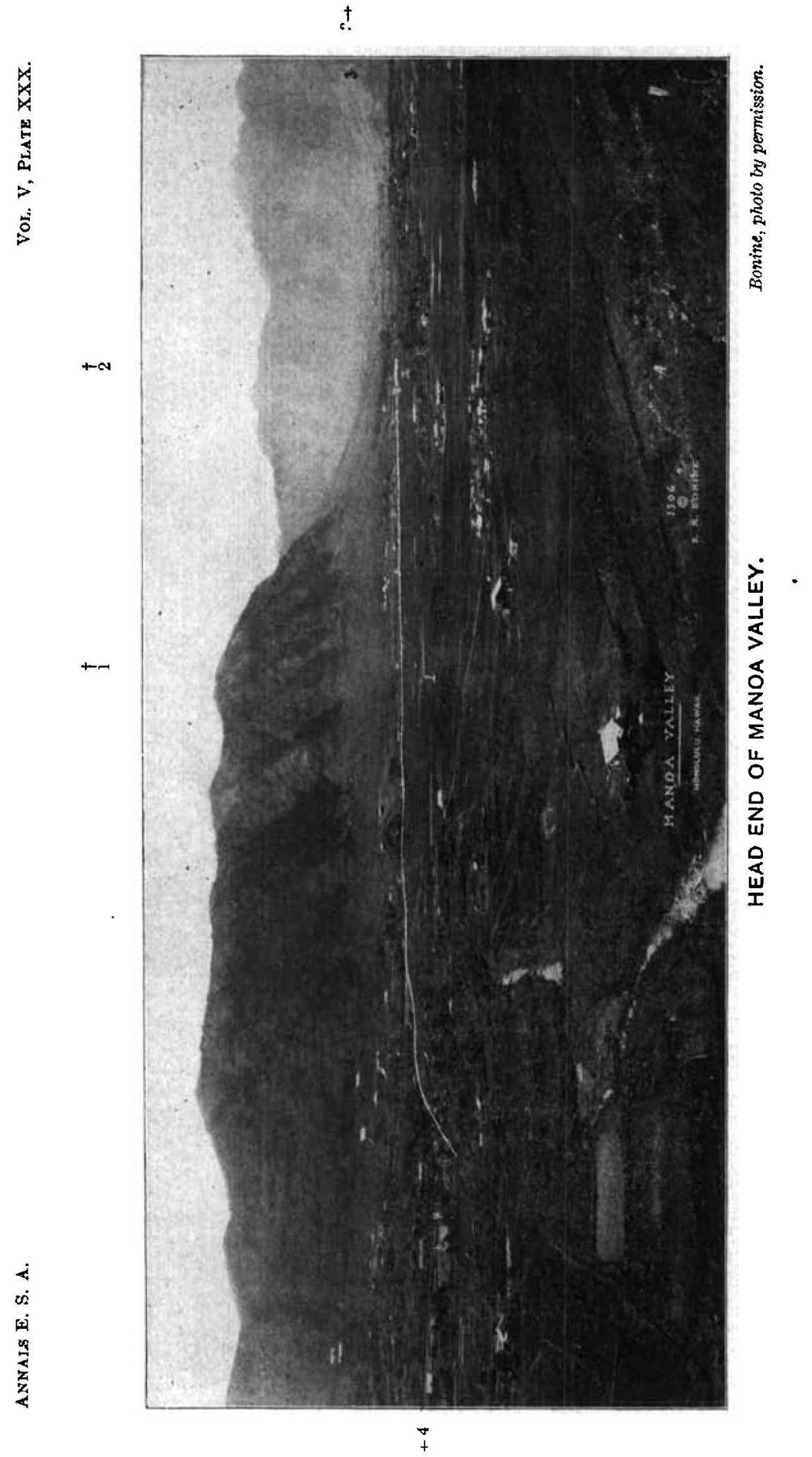

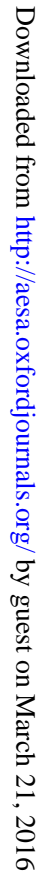

